\title{
Durability of bond strength to dentin using two universal adhesives in different etching modes
}

\author{
Amany A. Salem ${ }^{1}$ * (iD, Mohamed S. Nassif², Dalia I. \\ El-Korashy ${ }^{3}$
}

1 Instructor of Dental Biomaterials, Biomaterials Department, Faculty of Dentistry, Ain-Shams University, Organization of African Unity St, ElQobba Bridge, Al Waili, Cairo, Egypt.

${ }^{2}$ Professor of Dental Biomaterials, Biomaterials Department, Faculty of Dentistry, Ain-Shams University, Organization of African Unity St, ElQobba Bridge, Al Waili, Cairo, Egypt.

${ }^{3}$ Professor and Head of Biomaterials Department, Faculty of Dentistry, Ain-shams University, Organization of African Unity St, ElQobba Bridge, Al Waili, Cairo, Egypt.

*Corresponding author: Amany A. Salem

BDS, Instructor of Dental Biomaterials, Biomaterials Department, Faculty of Dentistry, Ain-Shams University, organization of African unity St, El-Qobba Bridge, Al Waili, Cairo, Egypt.

Email:dr.amany@dent.asu.edu.eg Address: 500 El Narges buildings, $5^{\text {th }}$ settlement, Cairo Governorate, Egypt.

Phone: 00201090555433

Received: July 10, 2020

Accepted: January 16, 2021
Aim. To evaluate the bond durability of two universal adhesives; mild and ultra-mild in both etch-and-rinse and self-etch modes after simulated in-vitro degradation by long-term water storage or thermocycling. Methods. A total of 144 specimens were used in this study; 120 specimens (prepared from 30 teeth) for microshear bond strength testing and fracture mode assessment, and 24 specimens for scanning electron microscopic evaluation (prepared from 24 teeth). Specimens were prepared from 54 recently extracted caries free third molars and randomly divided into 12 groups, according to the adhesive treatment (All Bond or Scotchbond Universal), etching mode (etch-andrinse or self-etch) and aging method (thermocycling or water storage). Each tooth was sectioned mesio-distally into two halves exposing free dentin surface for bonding where dentin substrate $1 \mathrm{~mm}$ below the dentino-enamel junction was used. After adhesive application and composite build up, specimens were tested in shear mode after storing in distilled water at $37^{\circ} \mathrm{C}$ for 24 hours or 1 year, or after being thermocycled between 5 and $55^{\circ} \mathrm{C}$ for 10,000 cycles $(n=10)$. Microshear bond strength ( $\mu$ SBS) was tested using a universal testing machine. Adhesive-dentin interface was examined using scanning electron microscope $(\mathrm{SEM})(\mathrm{n}=2)$. Data were analyzed using 3 way ANOVA and pairwise comparisons was performed using Bonferroni correction at significance level of $a \leq 0.05$. Results. Statistical analysis revealed non-significant difference for etching mode in both adhesives ( $p=0.596)$. After aging, the bond strength was only reduced in Scotchbond Universal after one year of water storage in both modes $(p<0.001)$. SEM evaluation revealed intact hybrid layer and longer resin tags for etch-and-rinse mode than selfetch mode of both adhesives. Conclusion. The bond strength of universal adhesives is not affected by the etching mode, however its durability was shown to be material dependent.

Keywords: Dental cements. Dentin. n^ntal bonding. 


\section{Introduction}

The success of most of the current esthetic restorations depends greatly on the quality of the bond between the tooth structure and the restorative material ${ }^{1}$. In this context, a great effort has been directed towards the development of dental adhesives that can achieve a strong bond to the tooth structure by relatively simple adhesive procedures ${ }^{2}$.

Recently, manufacturers have introduced a single product for all situations, referred to as 'universal' or 'multi-mode' adhesives ${ }^{3}$. Universal adhesives represent the last generation of adhesives in the market ${ }^{4}$. They are "universal" in two main ways: First, they are recommended by dental manufacturers for use both in etch-and-rinse and selfetch modes with claims by manufacturers that there is no compromise on bonding effectiveness when either bonding strategy is employed 5 . Second, they can be used on a wide range of substrates; they can be used to bond to dentin and enamel, for the placement of both direct and indirect restorations. Moreover, some universal adhesives can be used as adhesive primers on substrates such as zirconia, noble and non-precious metals, composites and various silica-based ceramics without the need for dedicated and separately placed primers ${ }^{6}$.

The immediate bond strength of contemporary adhesives are quite satisfactory, however the long term durability upon aging is more critical and more clinically relevant². The $\mathrm{pH}$ of universal adhesives greatly influences the long term stability and durability of the bond strength to dentin. Universal adhesives can be classified according to the $\mathrm{PH}$ into "ultra-mild $(\mathrm{pH}>2.5)$ or mild $(\mathrm{pH}>2)$ or intermediately strong $(\mathrm{pH}$ approximately equal 1.5). Generally, lower stability of bonding to dentin has been reported to intermediately strong universal adhesives after aging due to the high acidity of residual monomers that continue to demineralize the dentin and further weaken the adhesive interface ${ }^{4}$.

Resin-dentin bonds are more challenging and less durable than resin-enamel bonds. The limited durability of resin-dentin bonds severely compromises the lifetime of tooth-colored restorations ${ }^{7}$. This may be attributed to several factors including the heterogeneity of dentin composition (high organic and water content), the variation in the density of dentinal tubules with dentinal depth and the structural changes as in carious and sclerotic dentin which are usually accompanied with decrease in the dentin permeability ${ }^{8}$.

In contrast to clinical trials, simulated oral environment testing can be used to rapidly determine the relative bonding durability of materials. In-vitro degradation of restored teeth can be simulated allowing standardization of conditions before and after storage, and assessing degradation using various tests allows easy comparison?

Several methodologies of aging have been reported in literature such as water storage, thermocycling, mechanical loading as well as degradation by enzymes and various chemical substances among which water storage and thermocycling represent the most popular artificial aging methods ${ }^{10}$. Water is thought to play a major role in degradation of dentin-resin bond. In long-term water storage experiments, degradation is accelerated by hydrolysis of hydrophilic resin components and by host-derived proteases with collagenolytic activity. In addition, the restorations are clinically subjected to repetitive expansion and contraction stresses caused by temperature fluctu- 
ations within the oral cavity. These stresses have been proposed to affect the bonded interface. In thermocycling, the bonded specimens are subjected to cyclic temperature changes through water immersion?.

There are insufficient data in the literature regarding the effect of different aging methods on the performance of universal adhesives. Moreover, there is heterogeneity in the results of studies testing the long term durability of universal adhesives ${ }^{9,11-16}$ Hence, this study was designed to evaluate the effect of the application mode and the simulated in vitro degradation method on the micro-shear bond strength of two different universal adhesives. The null hypotheses were that (i) the application mode will not affect the microshear bond strength of an ultra-mild or mild universal adhesives, (ii) the bond strength is not affected by the simulated in vitro degradation methods.

\section{Material and Methods}

Materials: Adhesive systems, their description, composition and application procedures according to the manufacturer's instructions are shown in Table 1.

Table 1. Adhesive systems, their description, composition and application procedures according to the manufacturer's instructions.

\begin{tabular}{|c|c|c|c|}
\hline $\begin{array}{c}\text { Brand } \\
\text { name and } \\
\text { manufacturer }\end{array}$ & Description & Composition & Application procedures \\
\hline
\end{tabular}

\begin{tabular}{|c|c|c|c|}
\hline $\begin{array}{l}\text { Scotchbond } \\
\text { Universal (3M } \\
\text { ESPE, Neuss, } \\
\text { Germany) }\end{array}$ & $\begin{array}{l}\text { Mild } \\
\text { Universal } \\
\text { adhesive. } \\
(\mathrm{pH}=2.7)\end{array}$ & $\begin{array}{l}\text { MDP Monomer, } \\
\text { Dimethacrylate } \\
\text { resins, } \\
\text { HEMA, } \\
\text { Vitrebond }^{\mathrm{m}} \\
\text { Copolymer, } \\
\text { Fillers, } \\
\text { Ethanol, } \\
\text { Water, } \\
\text { Initiators, } \\
\text { Silane. }\end{array}$ & 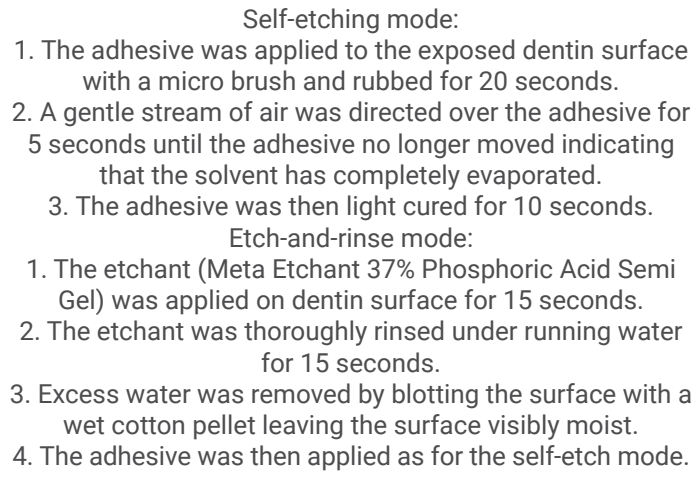 \\
\hline $\begin{array}{l}\text { All Bond } \\
\text { Universal } \\
\text { (Bisco, } \\
\text { Schaumburg, } \\
\text { Illinois, USA) }\end{array}$ & $\begin{array}{l}\text { Ultra-mild } \\
\text { Universal } \\
\text { adhesive. } \\
(\mathrm{pH}=3.2)\end{array}$ & $\begin{array}{c}\text { MDP, } \\
\text { Bis-GMA, } \\
\text { HEMA, } \\
\text { Ethanol, } \\
\text { Water, } \\
\text { Initiators. }\end{array}$ & $\begin{array}{l}\text { Self-etching mode: } \\
\text { 1. Two separate coats of adhesive were applied by scrubbing } \\
\text { the dentin surface with a microbrush for } 10 \text { s per coat (no } \\
\text { light polymerization was performed between coats). } \\
\text { 2. Excess solvent was evaporated by thoroughly air- } \\
\text { drying wi th an air syringe for } 10 \mathrm{~s} \text { until the adhesive no } \\
\text { longer moved, leaving the surface with a uniform glossy } \\
\text { appearance. } \\
\text { 4. The adhesive was then light cured for } 10 \mathrm{~s} \text {. } \\
\text { Etch-and-rinse mode: } \\
\text { 1. The etchant (Meta Etchant } 37 \% \text { Phosphoric Acid Semi } \\
\text { Gel) was applied on the dentin surface for } 15 \text { seconds. } \\
\text { 2. The etchant was thoroughly rinsed under running water } \\
\text { for } 15 \text { seconds. } \\
\text { 3. Excess water was removed by blotting the surface with a } \\
\text { wet cotton pellet leaving the surface visibly moist. } \\
\text { 4. The adhesive was then applied as for the self-etch mode. }\end{array}$ \\
\hline
\end{tabular}

MDP: Methacryloyloxydecyl dihydrogen phosphate, HEMA: Hydroxyethylmethacrylate, Bis-GMA: Bisphenol A glycidyl methacrylate. 


\section{Methods}

\section{Microshear bond strength testing}

\section{Specimens grouping}

A total of 144 specimens were used in this study; 120 specimens for microshear bond strength testing and fracture mode assessment, and 24 specimens for scanning electron microscope evaluation. The specimens were prepared from 54 recently extracted caries free third molars (30 teeth for microshear bond strength testing with 4 specimens prepared on each tooth and 24 for scanning electron microscopic evaluation). Molars were washed, cleaned from debris, stored in distilled water for 1 month. Then, they were randomly divided into twelve groups according to the aging method (24 hours of water storage, one year of water storage or thermocycling), the adhesive used (All Bond Universal or Single Bond Universal) and etching mode (etch-and-rinse or self-etch) where $n=10$ for micro-shear and $\mathrm{n}=2$ for SEM evaluation.

\section{Specimens preparation}

Each tooth was sectioned mesiodistally into two halves under copious air-water coolant spray by diamond disc (Honeycomb Design 6924, KOMET, USA). The roots of the teeth were then removed ${ }^{17}$.

Each sectioned half was embedded in chemically cured acrylic resin placed in a polyvinyl ring with enamel surface facing the acrylic and the cut surface facing upward exposing a free dentin surface for bonding. In each sectioned half, the portion of dentin substrate $1 \mathrm{~mm}$ below the dentino-enamel junction was used.

The exposed dentin surfaces were manually polished in a circular motion with a wet 600 -grit SiC paper for $60 \mathrm{~s}$ in order to standardize the smear layer ${ }^{3}$. The specimens were then cleaned ultrasonically to ensure removal of any debris from the surface ${ }^{18}$ and were randomly divided into twelve groups for microshear bond strength test $(n=10)$ according to the adhesive used (All Bond Universal or Scotchbond Universal), etching mode (etch-and-rinse or self-etch) and aging method (24 hours of water storage, one year of water storage or thermocycling). Each adhesive was strictly applied according to manufacturers' instructions as shown in table 1.

Two rubber microtubes (Tygon, Norton Performance Plastic Co., Akron, OH, USA) of $0.8 \mathrm{~mm}$ diameter and $1 \mathrm{~mm}$ height were then placed at different positions $1 \mathrm{~mm}$ below the dentinoenamel junction on the treated dentin surfaces. The adhesive was then light cured with the LED light curing device (Elipar S10 free light, 3M ESPE, USA) with an output intensity $1200 \mathrm{~mW} / \mathrm{cm}^{2}$ with the light curing device resting directly on the tubes.

The A2 shade Flowable Nano-Hybrid composite (Tetric $\mathrm{N}$ flow) was carefully inserted into the tubes, covered by a celluloid strip and light-irradiated with the LED light curing device. Then the tubes were carefully removed leaving the resin-bonded composite cylinders ${ }^{18}$.

\section{Aging method and testing procedures}

For the control group, specimens were stored in distilled water at $37^{\circ} \mathrm{C}$ for 24 hours ${ }^{19}$. 
For the water storage group, specimens were stored in distilled water at $37^{\circ} \mathrm{C}$ for 1 year ${ }^{9}$.

For the thermocycling group, specimens were stored in distilled water at $37{ }^{\circ} \mathrm{C}$ for 24 hours and were then subjected to 10,000 thermal cycles (TCs) between 5 and $55^{\circ} \mathrm{C}$ with a dwell time of $30 \mathrm{~s}$ and a transfer time of $5 \mathrm{~s}$ in a thermocycler (SD Mechatronic, Feldkirchen-Westerham Germany) ${ }^{20}$.

Microshear bond strength was tested by a Universal Testing Machine (Lloyd LR $5 \mathrm{k}$, Lloyd Instruments Ltd., Hampshire, UK). A thin steel wire $(0.18 \mathrm{~mm}$ diameter) was looped around the resin composite cylinder touching the tooth surface and attached to upper compartment parallel to the load cell movement direction and to the bonded surface 2122 .

Force was applied at a cross head speed of $1.0 \mathrm{~mm} / \mathrm{min}$ until failure ${ }^{23}$. Bond strength values were calculated by dividing the maximum debonding forces by the surface area automatically using (Nexygen software).

\section{Fracture mode analysis}

After debonding of each sample, the fractured interface was assessed using a stereomicroscope (Olympus Stereozoom SZ 40 Microscope, Tokyo, Japan) at magnification of 40X to determine the mode of failure which was classified as 'cohesive' (entirely within dentine substrate or resin composite), 'adhesive' (at the dentine-resin interface) or 'mixed' (at dentine-resin interface including failure into one of the substrates) ${ }^{19}$.

\section{Scanning electron microscopic evaluation of the tooth-restoration interface}

Scanning electron microscope analysis was carried out for assessment of the tooth restoration interface of the different experimental groups. Standard Class $V$ cavities were prepared in 24 recently extracted caries free third molars and randomly divided into the twelve groups where the number of specimens $(n=2)$ for each experimental condition as described for microshear bond strength test. The adhesive system and resin composite were then applied to the exposed dentin of class $\mathrm{V}$. The teeth were stored in distilled water for 24 hours then sectioned bucco-lingually using a diamond disc under water coolant. The sections were flattened and smoothed using silicon carbide papers with sequential grit of 400,600, and 1000 under water. The specimens were acid etched using a 37\% phosphoric acid gel for 5 seconds and rinsed for another 30 seconds. The specimens were then immersed in a $3 \% \mathrm{NaOCl}$ for five minutes. Then the specimens were placed in $70 \%, 80 \%, 90 \%$, and $99 \%$ alcohol to eliminate all the water present ${ }^{24}$.

The specimens were gold sputtered (Emitech K550X sputter coater, East Sussex, England) and the adhesive/dentin interface was evaluated using scanning electron microscope (Quanta 250 FEG Field Emission Gun), with an accelerating voltage 30 K.V. at magnification of $3000 \mathrm{X}$.

\section{Statistical analysis}

Numerical data were explored for normality using Kolmogorov-Smirnov and Shapiro-Wilk tests. Data showed parametric distribution so; it was represented by 
mean and standard deviation (SD) values. Levene's test was performed and the result was not significant so there was homogeneity of variances. Three-way ANOVA was then used to study the effect of different tested variables (adhesive, etching mode and aging method) and their interaction. Comparison of main and simple effects was done utilizing Bonferroni correction. The significance level was set at $a \leq 0.05$ within all tests. Statistical analysis was performed with IBM (IBM Corporation, NY, USA.) SPSS (SPSS, Inc., an IBM Company). Statistics Version 25 for Windows.

\section{Results}

\section{Micro-Shear bond strength results}

Mean and standard deviation (SD) values of micro-shear bond strength (MPa) for different aging methods $(p<0.001)$, adhesives $(p=0.001)$ and etching modes $(p=0.596)$ are presented in table 2.

In the control group, Scotchbond Universal adhesive showed significantly higher bond strength than All Bond Universal in both etching modes. After one year of water storage, All Bond Universal adhesive retained its bond strength for both modes. However, the bond strength of Scotchbond Universal was significantly reduced when compared with immediate bond strength. After thermocycling, statistical analysis revealed no significant difference between the immediate and thermocycled groups for both All Bond Universal adhesive and Scotchbond Universal as shown in table 2. Regarding the effect of the etching mode, both adhesives showed no significant difference in bond strength either in the self-etch or the etch-and-rinse mode under all aging methods $(p=0.596)$.

Table 2. Mean \pm standard deviation (SD) values of micro-shear bond strength (MPa) for the effect of different aging methods, adhesives and etching modes.

\begin{tabular}{lccccc}
\hline \multirow{2}{*}{$\begin{array}{l}\text { Etching } \\
\text { mode }\end{array}$} & Adhesive & Control & $\begin{array}{c}\text { One year water } \\
\text { storage }\end{array}$ & $\begin{array}{c}\text { Thermo } \\
\text { Cycling }\end{array}$ & \multirow{2}{*}{ p-value } \\
\cline { 2 - 5 } & Scotchbond Universal & $20.55 \pm 3.19^{\mathrm{Aa}}$ & $12.78 \pm 1.96^{\mathrm{Ba}}$ & $17.75 \pm 3.43^{\mathrm{Aa}}$ & $<0.001^{*}$ \\
\hline \multirow{2}{*}{$\begin{array}{l}\text { Self- } \\
\text { etch }\end{array}$} & All Bond Universal & $15.94 \pm 2.64^{\mathrm{Ab}}$ & $14.67 \pm 2.05^{\mathrm{Aa}}$ & $14.05 \pm 2.03^{\mathrm{Ab}}$ & $0.268 \mathrm{~ns}$ \\
\cline { 2 - 5 } & p-value & $<0.001^{*}$ & $0.112 \mathrm{~ns}$ & $0.003^{*}$ & \\
\hline \multirow{2}{*}{$\begin{array}{l}\text { Etch- } \\
\text { and- } \\
\text { rinse }\end{array}$} & Scotchbond Universal & $19.11 \pm 2.39^{\mathrm{Aa}}$ & $11.18 \pm 3.65^{\mathrm{Bb}}$ & $18.83 \pm 1.85^{\mathrm{Aa}}$ & $<0.001^{*}$ \\
\cline { 2 - 5 } & All Bond Universal & $15.40 \pm 3.38^{\mathrm{Ab}}$ & $14.90 \pm 2.80^{\mathrm{Aa}}$ & $14.77 \pm 1.70^{\mathrm{Ab}}$ & $0.864 \mathrm{~ns}$ \\
\cline { 2 - 5 } & p-value & $0.004^{*}$ & $0.004^{*}$ & $0.002^{*}$ & \\
\hline
\end{tabular}

Different upper and lowercase superscript letters indicate a statistically significant difference within the same row or column respectively*; significant $(p \leq 0.05)$ ns; non-significant $(p>0.05)$

\section{Failure mode analysis}

In Immediate groups, the predominant failure mode was adhesive failure followed by mixed failure with remnants of adhesive and composite on the dentin surface, a similar tendency was found for thermocycled specimens. In water storage groups, the predominant mode of failure was adhesive failure as shown in table 3. 
Table 3. Bond failure mode for different groups.

\begin{tabular}{|c|c|c|c|c|c|c|c|c|c|c|c|c|}
\hline \multirow{3}{*}{$\begin{array}{l}\text { Mode of } \\
\text { failure }\end{array}$} & \multicolumn{11}{|c|}{ Aging Methods } & \\
\hline & \multicolumn{4}{|c|}{ Control } & \multicolumn{4}{|c|}{ One-year water storage } & \multicolumn{4}{|c|}{ Thermocycling } \\
\hline & SBSE & SBER & ABSE & ABER & SBSE & SBER & ABSE & ABER & SBSE & SBER & ABSE & ABER \\
\hline $\begin{array}{l}\text { Adhesive } \\
\text { failure }\end{array}$ & $70 \%$ & $80 \%$ & $70 \%$ & $60 \%$ & $100 \%$ & $100 \%$ & $80 \%$ & $90 \%$ & $90 \%$ & $100 \%$ & $80 \%$ & $80 \%$ \\
\hline $\begin{array}{l}\text { Cohesive } \\
\text { failure }\end{array}$ & 0 & 0 & 0 & 0 & 0 & 0 & 0 & 0 & 0 & 0 & 0 & 0 \\
\hline $\begin{array}{l}\text { Mixed } \\
\text { failure }\end{array}$ & $30 \%$ & $20 \%$ & $30 \%$ & $40 \%$ & 0 & 0 & $20 \%$ & $10 \%$ & $10 \%$ & 0 & $20 \%$ & $20 \%$ \\
\hline
\end{tabular}

SBSE: Scotchbond Universal self etch, SBER: Scotchbond Universal etch and rinse.

ABSE: All Bond Universal self etch, ABER: All Bond Universal etch and rinse.

\section{Scanning Electron Microscope evaluation results}

In the control and thermocycling groups, both adhesives showed good integrity at the adhesive- dentin interface with intact hybrid layer formation and numerous long intact resin tags formation in the etch-and-rinse mode with mean length of resin tags of $21.13 \mu \mathrm{m}, 23.1 \mu \mathrm{m}$, $21.7 \mu \mathrm{m}, 24.5 \mu \mathrm{m}$ in SBER control, ABER control, SBER thermocycling and ABER thermocycling groups respectively. However, in the self-etch mode a less distinct hybrid layer is seen with very few resin tags in case of Scotchbond Universal adhesive and absence of resin tags in case of All Bond Universal adhesive as shown in figures 1 and 2.
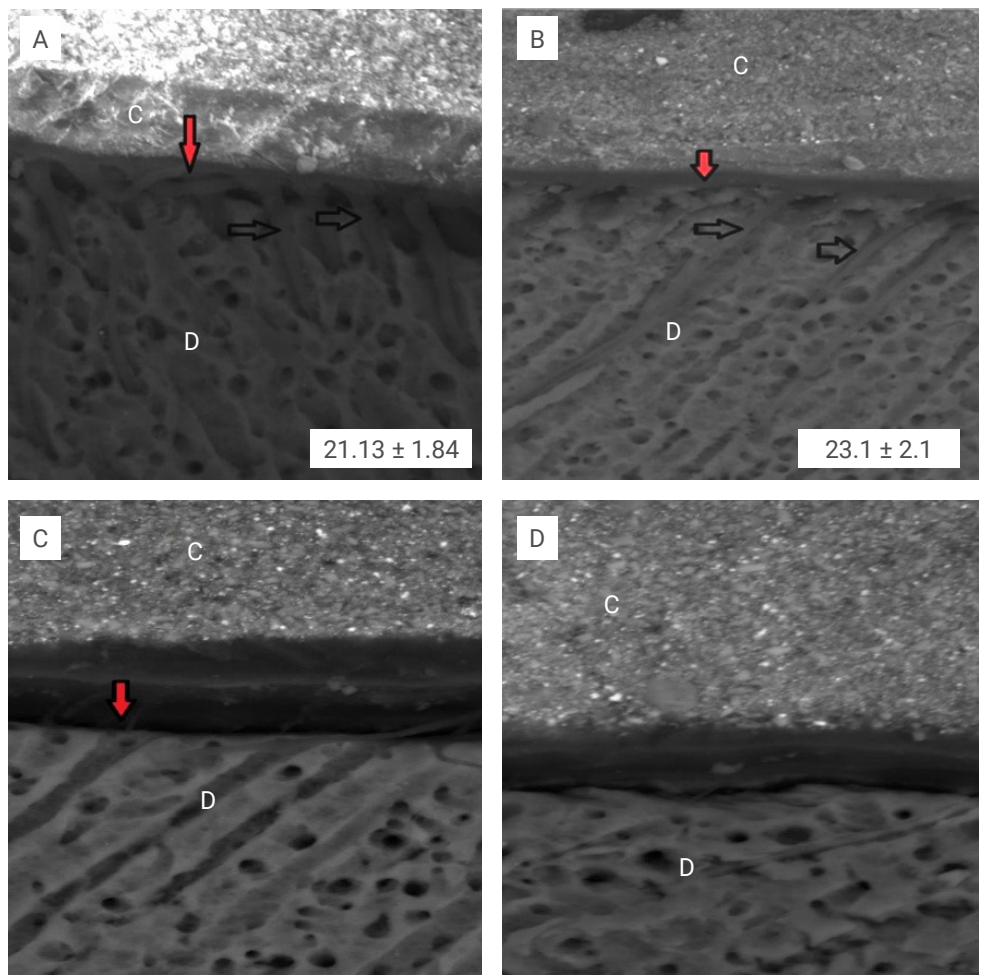

Figure 1. SEM image 3000X showing tooth /restoration interface in the control group, (A) Scotchbond Universal etch-and-rinse mode; (B) All Bond Universal etch-and-rinse mode; (C) Scotchbond Universal selfetch mode; (D) All Bond Universal self-etch mode (D) dentin; (C) composite; Red arrows marking the hybrid layer; White arrows marking the resin tags, rectangle: mean length $(\mu \mathrm{m})$ of resin tags \pm standard deviation 

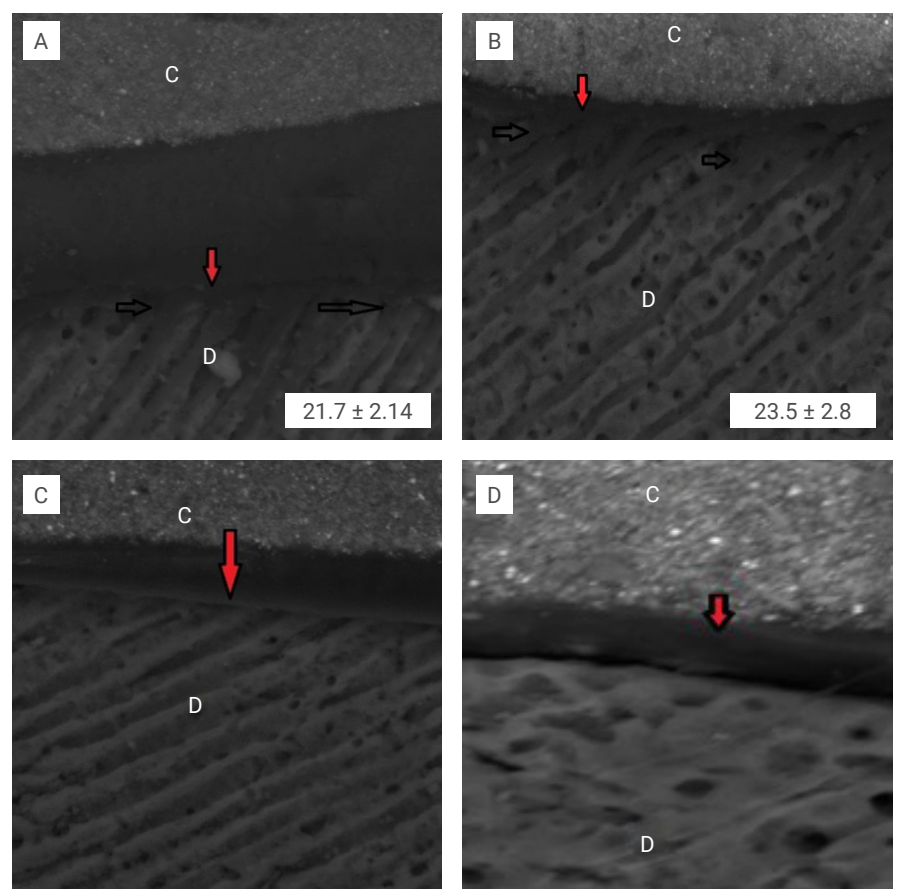

Figure 2. SEM image 3000X showing tooth restoration interface after thermocycling, (A) Scotchbond Universal etch-and-rinse mode; (B) All Bond Universal etch-and-rinse mode; (C) Scotchbond Universal self-etch mode; (D) All Bond Universal self-etch mode; (D) dentin; (C) composite; Red arrows marking the hybrid layer; White arrows marking the resin tags, rectangle: mean length $(\mu \mathrm{m})$ of resin tags \pm standard deviation.

After one year of water storage, in Scotchbond Universal adhesive there was a clear deterioration in the hybrid layer with gap formation in both modes. On the other hand, in case of All Bond Universal adhesive a continuous hybrid layer is retained in both modes, with long resin tags in the etch-and-rinse mode as shown in figure 3. 

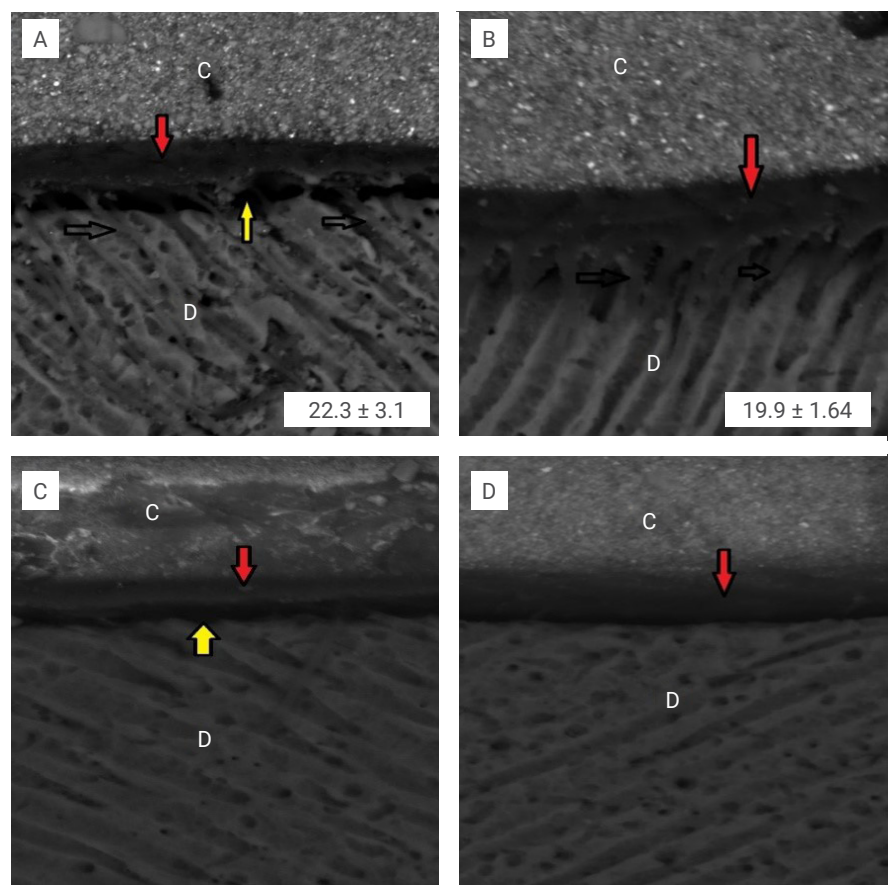

Figure 3. SEM image 3000X showing tooth/restoration interface after one year water storage, (A) Scotchbond Universal etch-and-rinse mode; (B) All Bond Universal etch-and-rinse mode; (C) Scotchbond Universal self-etch mode; (D) All Bond Universal self-etch mode (D) dentin; (C) composite; Red arrows marking the hybrid layer; White arrows marking the resin tags; yellow arrows marking gaps, rectangle: mean length $(\mu \mathrm{m})$ of resin tags \pm standard deviation.

\section{Discussion}

Adhesive technology has been well developed over the past few decades ${ }^{25}$. Universal adhesives are claimed to offer the versatility of being used in either etch-and-rinse or self-etch modes to bond direct and indirect restorations ${ }^{6}$. In the present study, the two adhesives (Scotchbond Universal and All Bond Universal adhesives) have been evaluated to determine their dentin bonding ability under different etching modes and after aging.

Although both adhesives are marketed as universal adhesives, they differ from each other in the composition ${ }^{26}$. In the control group, the bond strength of Scotchbond Universal didn't change significantly regardless the etching mode. This was in agreement with the studies carried out by Marchesi et al. ${ }^{14}$ and Munoz et al. ${ }^{3}$. Similarly, the bond strength of All Bond Universal adhesive didn't change significantly regardless the etching mode. This was in agreement with a study carried out by Wanger et al. ${ }^{19}$. Yet other studies ${ }^{3,27}$ showed that there was a drop in the bond strength of All bond universal in the self-etch mode when compared to the etch-and-rinse mode. The application of All Bond Universal without active brushing, was considered the main reason for the decrease in the bond strength in the self-etch mode. It has been demonstrated that active application of adhesives improves their bonding performance in the selfetch mode ${ }^{28}$. In the present study, All Bond Universal was applied by scrubbing the preparation surface according to the manufacturer's instructions, which could explain the similar bond strength results in both modes $^{19}$. 
However, the bond strength of Scotchbond Universal was higher than All bond universal. This may be attributed to the presence of fillers in the composition of Scotchbond Universal. Many authors ${ }^{29-32}$ have reported higher bond strength for adhesive systems with incorporated filler particles than for unfilled products. This may be because the addition of fillers increases the cohesive strength of the adhesive itself and plays a role in increasing the fracture resistance of the dentin-adhesive interface ${ }^{33}$. Additionally, these nano-sized fillers may infiltrate into the demineralized tubules and intertubular dentin stabilizing the hybrid layer ${ }^{9,34}$.

In the present study, the results of long-term water storage showed that responses to one year of water storage differ between the two adhesives. All Bond Universal adhesive retained its bond strength after one year of water storage. On the contrary, the bond strength of the Scotchbond Universal dropped for both bonding techniques. This was in agreement with study conducted by Sai et al. ${ }^{9}$ So, the second null hypothesis is rejected.

The bond stability of All bond universal adhesives after water storage, may be explained by the presence hydrophobic MDP functional monomers in their composition. These monomers are capable of bonding chemically to dentin, since MDP contains a polymerizable methacrylate group and a phosphate group capable of forming a stable salt with the calcium in hydroxyapatite ${ }^{35}$. In addition, the MDP monomers self assemble in hydrophobic nanolayers, which increases the strength of the adhesive interface ${ }^{3}$. It has been found that these water insolouble 10-MDP calcium salts have no effect on the immediate bond strength but contribute to the bond stability through protecting the hybrid layer from hydrolytic degradation ${ }^{5}$. Although Scotchbond Universal adhesive also contains MDP monomers, the bond strength dropped in both modes after water storage. This might be attributed to the presence of poly-alkenoic acid copolymer (VitrebondTM) in its composition. Poly-alkenoic acid copolymer bonds chemically and spontaneously to hydroxyapatite in dentin, Yoshida et al. ${ }^{36}$ postulated that poly-alkenoic acid copolymer may compete with the MDP present in Scotchbond Universal reducing 10-MDP-calcium salts within the resin dentine interface $^{5}$. Moreover, it was postulated that the presence of polyalkenoic acid copolymer could have prevented the monomer approximation during polymerization resulting in a lower degree of conversion.

In one study ${ }^{3}$, where the degree of conversion of universal adhesives was measured, a decreased degree of conversion was found for Scotchbond Universal when compared to other adhesives including All- Bond Universal. The decreased degree of conversion and presence of unreacted monomers within the hybrid layer would increase the permeability of the adhesive layer, and thus decreasing the hydrolytic stability of the dental adhesive consequently reducing the interfacial strength of the adhesive interface ${ }^{37}$.

Another study ${ }^{38}$ measuring the extent of oxygen inhibition on free radical polymerization of several universal adhesives, found that Scotchbond Universal adhesives exhibited higher inhibition. Moreover, the oxygen inhibition was not limited to the layer exposed to atmospheric oxygen but air bubbles were also incorporated in the adhesive film. These structural defects associated with oxygen inhibition were assumed to affect the long term stability and durability of the adhesive ${ }^{39}$. 
Additionally, in contrast to All Bond Universal, Scotchbond Universal contains silane in its composition. It was postulated that silane could increase the hydrophilicity of Scotchbond Universal, thereby increasing the susceptibility of the adhesive layer to hydrolytic degradation ${ }^{40}$. All the abovementioned reasons may account for the decrease in the bond strength of Scotchbond Universal adhesive upon water storage.

The second in-vitro degradation method used in the present study was the effect of thermocycling on the bond strength of universal adhesives. During thermocycling, specimens were subjected to thermal stresses in addition to the exposure to water. So thermocycling is expected to affect the bond strength in two ways; first through the stresses generated at the tooth-restoration interface due to the mismatch in the coefficient of thermal expansion and contraction between the restorative material and the tooth tissues ${ }^{19}$. Second, the hot water may accelerate hydrolysis of non-protected collagen and extract poorly polymerized resin oligomers ${ }^{41}$.

It has been postulated that 10,0000 cycles correspond to 1 year of clinical service, based on the hypothesis that around 20 - 30 cycles might occur intraorally per day ${ }^{42}$. Another variable in the thermocycling protocol is the dwell time. It is the period of time that the specimen is immersed in a bath of a particular temperature. It represents the latency period that the oral capacity needs to reach its normal temperature again, after consuming hot or cold food and drink. A short dwell time of 10-15 s was suggested by several authors relying on the limited tolerance of patients to direct contact between vital tooth and extremely hot or cold substances ${ }^{43}$.

In literature, there is controversy on the effect of thermocycling on the bond strength. Some studies reported that thermocycling had no effect on bond strength to dentin, while others showed that it decreased the bond strength significantly ${ }^{19,44-46}$. In the present study, thermocycling had no effect on the bond strength of both adhesives. This may be justified by suggesting that higher temperatures during thermocycling induce secondary curing of unreacted monomers ${ }^{9}$. This secondary curing may result in higher resistance to the generated stresses and may overcome the hydrolytic effect of thermocycling since the susceptibility of resin to hydrolysis may result from a low degree of conversion ${ }^{47}$.

The higher bond strength of Single Bond Universal than All Bond Universal after thermocycling can be due the presence of fillers in its composition. It has been postulated that the addition of fillers not only reinforces the hybrid layer but also make the coefficient of thermal expansion of the adhesive resin closer to those of the dentin and resin based composites ${ }^{48}$. From the results of this study, the application mode didn't affect the bond strength results in both adhesives in different groups. So the first null hypothesis is accepted.

The bond strength results were further justified by SEM findings. Upon evaluation of the generated interface by SEM, the adhesive interface morphology of the control groups revealed close morphological appearance to that of the thermocycling groups. In the self-etch mode of Scotchbond Universal, the hybrid layer was very thin with very few resin tags. In case of All Bond Universal, there was absence of hybrid layer and resin tags which may be explained by its ultramild acidity ${ }^{49}$. In case of etch-andrinse mode, acid etching resulted in removal of smear layer and smear plugs, deeper 
penetration of both universal adhesives into dentin with formation of long resin tags and thicker hybrid layers when compared to the self-etch mode. Although there was a better interface morphology after acid etching, no relationship was observed between the quality of the hybrid layer (i.e., percentage of adhesive penetration)and bond strength $^{50}$. In this study, there was no difference in the immediate bond strength of etch-and-rinse as well as self-etched dentin in both adhesives.

In case of water storage, the SEM analysis showed deterioration in the hybrid layer with gap formation after one year of water storage in either modes in case of Scotchbond Universal adhesive. However, in case of All bond universal adhesive, the SEM micrographs showed that a continuous hybrid layer was retained in both modes, with long resin tags in the etch-and-rinse mode. This supports the bond strength results in the water storage.

Regarding the failure mode, it did not seem to follow any pattern in relation to treatment type. The predominant failure mode was adhesive failure regardless the degradation condition or etching mode.

From this study, it can be concluded that universal adhesives represent a new class of adhesives that can be used in self-etch or etch-and-rinse mode without altering the bond strength to dentin. However, the durability of these adhesives depends greatly on the composition of these adhesives. More studies with different degradation methodologies are required to ensure the long term durability of universal adhesives.

\section{Funding}

This research did not receive any specific grant from funding agencies in the public, commercial, or not-for-profit sectors.

\section{References}

1. Vaidyanathan TK, Vaidyanathan J. Recent advances in the theory and mechanism of adhesive resin bonding to dentin: a critical review. J Biomed Mater Res B Appl Biomater. 2009 Feb;88(2):558-78. doi: 10.1002/jbm.b.31253.

2. Nagarkar S, Theis-Mahon N, Perdigão J. Universal dental adhesives: Current status, laboratory testing, and clinical performance. J Biomed Mater Res B Appl Biomater. 2019 Aug;107(6):2121-31. doi: $10.1002 / j b m \cdot b .34305$.

3. Muñoz MA, Luque I, Hass V, Reis A, Loguercio AD, Bombarda NHC. Immediate bonding properties of universal adhesives to dentine. J Dent. 2013 May;41(5):404-11. doi: 10.1016/j.jdent.2013.03.001.

4. Cuevas-Suarez CE, da Rosa WLO, Lund RG, da Silva AF, Piva E. Bonding performance of universal adhesives: an updated systematic review and meta-analysis. J Adhes Dent. 2019;21(1):7-26. doi: 10.3290/j.jad.a41975.

5. Chen C, Niu L-N, Xie H, Zhang Z-Y, Zhou L-Q, Jiao K, et al. Bonding of universal adhesives to dentine-Old wine in new bottles? J Dent. 2015 May;43(5):525-36. doi: 10.1016/j.jdent.2015.03.004.

6. Alex G. Universal adhesives: the next evolution in adhesive dentistry. Compend Contin Educ Dent. 2015 Jan;36(1):15-26; quiz 28, 40.

7. Liu Y, Tjäderhane L, Breschi L, Mazzoni A, Li N, Mao J, et al. Limitations in bonding to dentin and experimental strategies to prevent bond degradation. J. Dent. Res. 2011 Aug;90(8):953-68. doi: $10.1177 / 0022034510391799$. 
8. Sofan E, Sofan A, Palaia G, Tenore G, Romeo U, Migliau G. Classification review of dental adhesive systems: from the IV generation to the universal type. Ann Stomatol. 2017 Jul 3;8(1):1-17. doi: 10.11138/ads/2017.8.1.001.

9. Sai K, Shimamura Y, Takamizawa T, Tsujimoto A, Imai A, Endo H, et al. Influence of degradation conditions on dentin bonding durability of three universal adhesives. J Dent. 2016 Nov;54:56-61. doi: 10.1016/j.jdent.2016.09.004.

10. Van Meerbeek B, Peumans M, Poitevin A, Mine A, Van Ende A, Neves A, et al. Relationship between bond-strength tests and clinical outcomes. Dent Mater J. 2010 Feb;26(2):e100-21. doi: 10.1016/j. dental.2009.11.148.

11. Zhang Z-y, Tian F-c, Niu L-n, Ochala K, Chen C, Fu B-p, et al. Defying ageing: An expectation for dentine bonding with universal adhesives? J Dent. 2016 Feb;45:43-52. doi: 10.1016/j. jdent.2015.11.008.

12. Kaczor K, Gerula-Szymanska A, Smektala T, Safranow K, Lewusz K, Nowicka A. Effects of different etching modes on the nanoleakage of universal adhesives: a systematic review and meta-analysis. J Esthet Restor Dent. 2018 Jul;30(4):287-98. doi: 10.1111/jerd.12375.

13. Sezinando A, Perdigao J, Ceballos L. Long-term In vitro adhesion of polyalkenoate-based adhesives to dentin. J Adhes Dent. 2017;19(4):305-16. doi: 10.3290/j.jad.a38895.

14. Marchesi G, Frassetto A, Mazzoni A, Apolonio F, Diolosa M, Cadenaro M, et al. Adhesive performance of a multi-mode adhesive system: 1-year in vitro study. J Dent. 2014 May;42(5):603-12. doi: 10.1016/j.jdent.2013.12.008.

15. Lezaja Zebic M, Dzeletovic B, Miletic V. Microtensile bond strength of universal adhesives to flat versus Class I cavity dentin with pulpal pressure simulation. J Esthet Restor Dent. 2018 May;30(3):240-8. doi: 10.1111/jerd.12363.

16. Manfroi FB, Marcondes ML, Somacal DC, Borges GA, Junior LH, Spohr AM. Bond strength of a novel one bottle multi-mode adhesive to human dentin after six months of storage. Open Dent. 2016 Jun;10:268-77. doi: 10.2174/1874210601610010268.

17. Perdigao J, Swift Jr E, Denehy G, Wefel J, Donly K. In vitro bond strengths and SEM evaluation of dentin bonding systems to different dentin substrates. J. Dent. Res. 1994 Jan;73(1):44-55. doi: 10.1177/00220345940730010601.

18. Zhang L, Wang D-y, Fan J, Li F, Chen Y-j, Chen J-h. Stability of bonds made to superficial vs. deep dentin, before and after thermocycling. Dent Mater J. 2014 Nov;30(11):1245-51. doi: 10.1016/j. dental.2014.08.362.

19. Wagner A, Wendler M, Petschelt A, Belli R, Lohbauer U. Bonding performance of universal adhesives in different etching modes. J Dent. 2014 Jul;42(7):800-7. doi: 10.1016/j.jdent.2014.04.012.

20. Tsujimoto A, Barkmeier WW, Takamizawa T, Wilwerding T, Latta MA, Miyazaki M. Interfacial characteristics and bond durability of universal adhesive to various substrates. Oper. Dent. 2017;42(2):E59-E70. doi: 10.2341/15-353-L.

21. Sadr A, Ghasemi A, Shimada Y, Tagami J. Effects of storage time and temperature on the properties of two self-etching systems. J Dent. 2007 Mar;35(3):218-25. doi: 10.1016/j.jdent.2006.08.004.

22. Harnirattisai C, Roengrungreang P, Rangsisiripaiboon U, Senawongse P. Shear and micro-shear bond strengths of four self-etching adhesives measured immediately and 24 hours after application. Dent Mater J. 2012;31(5):779-87. doi: 10.4012/dmj.2012-013.

23. Cheetham JJ, Palamara JE, Tyas MJ, Burrow MF. A comparison of the micro-shear bond strength and failure mode of non-enclosed and mold-enclosed luting cements bonded to metal. Dent Mater J. 2013;32(6):896-905. doi: 10.4012/dmj.2013-065.

24. Lafuente D. SEM analysis of hybrid layer and bonding interface after chlorhexidine use. Oper. Dent. 2012;37(2):172-80. doi: 10.2341/10-251-L. 
25. Van Meerbeek B, Yoshihara K, Yoshida Y, Mine A, De Munck J, Van Landuyt K. State of the art of selfetch adhesives. Dent Mater J. 2011 Jan;27(1):17-28. doi: 10.1016/j.dental.2010.10.023.

26. Costa DM, Somacal DC, Borges GA, Spohr AM. Bond capability of universal adhesive systems to dentin in self-etch mode after short-term storage and cyclic loading. Open Dent J. 2017 Jun 30;11:276-83. doi: 10.2174/1874210601711010276.

27. Lee I-S, Son S, Hur B, Kwon Y-H, Park J-K. The effect of additional etching and curing mechanism of composite resin on the dentin bond strength. J Adv Prosthodont. 2013 Nov;5(4):479-84. doi: 10.4047/jap.2013.5.4.479.

28. Pleffken PR, de Almeida Lourenco AP, Torres C, Buhler Borges A. Influence of application methods of self-etching adhesive systems on adhesive bond strength to dentin. J Adhes Dent. 2011 Dec;13(6):517-25. doi: 10.3290/j.jad.a21417.

29. Fortin D, Swift Jr EJ, Denehy GE, Reinhardt JW. Bond strength and microleakage of current dentin adhesives. Dent Mater J. 1994 Jul;10(4):253-8. doi: 10.1016/0109-5641(94)90070-1.

30. Wakefield CW, Draughn RA, Sneed WD, Davis TN. Shear bond strengths of six bonding systems using the pushout method of in vitro testing. Oper. Dent. 1998;23(2):69-76.

31. Haller B. Recent developments in dentin bonding. Am J Dent. 2000 Feb;13(1):44-50.

32. Frankenberger R, Perdigao J, Rosa BT, Lopes M. "No-bottle" vs "multi-bottle" dentin adhesives--a microtensile bond strength and morphological study. Dent Mater J. 2001 Sep;17(5):373-80. doi: 10.1016/s0109-5641(00)00084-1.

33. Baracco B, Fuentes MV, Garrido MA, González-López S, Ceballos L. Effect of thermal aging on the tensile bond strength at reduced areas of seven current adhesives. Odontology. 2013 Jul;101(2):17785. doi: 10.1007/s10266-012-0073-2.

34. Carvalho CN, Francci CE, Costa JF, Bauer J. Effect of filler and application mode on micro-shear bond strength of etch-and-rinse adhesive systems. Rev Port Estomatol Cir Maxilofac. 2015;56(2):89-94. doi: 10.1016/j.rpemd.2015.05.002

35. Lawson NC, Robles A, Fu CC, Lin CP, Sawlani K, Burgess JO. Two-year clinical trial of a universal adhesive in total-etch and self-etch mode in non-carious cervical lesions. J Dent. 2015 Oct;43(10):1229-34. doi: 10.1016/j.jdent.2015.07.009.

36. Yoshida Y, Yoshihara K, Nagaoka N, Hayakawa S, Torii Y, Ogawa T, et al. Self-assembled nano-layering at the adhesive interface. J. Dent. Res. 2012 Apr;91(4):376-81. doi: $10.1177 / 0022034512437375$.

37. Hass V, Dobrovolski M, Zander-Grande C, Martins GC, Gordillo LA, Rodrigues Accorinte Mde L, et al. Correlation between degree of conversion, resin-dentin bond strength and nanoleakage of simplified etch-and-rinse adhesives. Dent Mater J. 2013 Sep;29(9):921-8. doi: 10.1016/j.dental.2013.05.001.

38. Papadogiannis D, Dimitriadi M, Zafiropoulou M, Gaintantzopoulou M-D, Eliades G. Universal adhesives: setting characteristics and reactivity with dentin. Materials (Basel). 2019 May 27;12(10):1720. doi: 10.3390/ma12101720.

39. Hashimoto M, Fujita S, Endo K, Ohno H. In vitro degradation of resin-dentin bonds with onebottle self-etching adhesives. Eur J Oral Sci. 2009 Oct;117(5):611-7. doi: 10.1111/j.16000722.2009.00664.x.

40. Kim J, Chae S, Lee Y, Han G, Cho B. Effects of multipurpose, universal adhesives on resin bonding to zirconia ceramic. Oper Dent. 2015;40(1):55-62. doi: 10.2341/13-303-L.

41. De Munck J, Van Landuyt K, Coutinho E, Poitevin A, Peumans M, Lambrechts P, et al. Micro-tensile bond strength of adhesives bonded to Class-I cavity-bottom dentin after thermo-cycling. Dent Mater J. 2005 Nov;21(11):999-1007. doi: 10.1016/j.dental.2004.11.005. 
42. Morresi AL, D’Amario M, Capogreco M, Gatto R, Marzo G, D'Arcangelo C, et al. Thermal cycling for restorative materials: does a standardized protocol exist in laboratory testing? a literature review. J Mech Behav Biomed Mater. 2014 Jan;29:295-308. doi: 10.1016/j.jmbbm.2013.09.013.

43. Amaral FL, Colucci V, Palma-Dibb RG, Corona SA. Assessment of in vitro methods used to promote adhesive interface degradation: a critical review. J Esthet Restor Dent. 2007;19(6):340-53; discussion 354. doi: 10.1111/j.1708-8240.2007.00134.x.

44. Gale MS, Darvell BW. Thermal cycling procedures for laboratory testing of dental restorations. J Dent. 1999 Feb;27(2):89-99. doi: 10.1016/s0300-5712(98)00037-2.

45. Abo-Hamar SE, Hiller KA, Jung H, Federlin M, Friedl KH, Schmalz G. Bond strength of a new universal self-adhesive resin luting cement to dentin and enamel. Clin Oral Investig. 2005 Sep;9(3):161-7. doi: 10.1007/s00784-005-0308-5.

46. Shirai K, De Munck J, Yoshida Y, Inoue S, Lambrechts P, Suzuki K, et al. Effect of cavity configuration and aging on the bonding effectiveness of six adhesives to dentin. Dent Mater J, 2005 Feb;21(2):11024. doi: 10.1016/j.dental.2004.01.003

47. Helvatjoglu-Antoniades M, Koliniotou-Kubia E, Dionyssopoulos P. The effect of thermal cycling on the bovine dentine shear bond strength of current adhesive systems. J. Oral Rehabil. 2004 Sep;31(9):911-7. doi: 10.1111/j.1365-2842.2004.01318.x.

48. Fanning DE, Wakefield CW, Robbins JW, Bagley AL. Effect of a filled adhesive on bond strength in three dentinal bonding systems. Gen Dent. 1995;43(3):256-62.

49. Ermis RB, De Munck J, Cardoso MV, Coutinho E, Van Landuyt KL, Poitevin A, et al. Bond strength of self-etch adhesives to dentin prepared with three different diamond burs. Dent Mater J. 2008 Jul;24(7):978-85. doi: 10.1016/j.dental.2007.11.019.

50. Perdigao J, Sezinando A, Monteiro PC. Laboratory bonding ability of a multi-purpose dentin adhesive. Am J Dent. 2012;25(3):153-8. 